\title{
EXPERIMENTAL SCRUTINIZATION OF HEAT TRANSFER CHARACTERISTICS ON TWO-PHASE FLOW IN 1-2 SHELL AND TUBE HEAT EXCHANGER
}

\author{
Saravanan A.M. ${ }^{1}$, Jeykumar M. ${ }^{2}$, Sundaram S. ${ }^{3}$ \\ ${ }^{1}$ Department of Chemical Engineering, St. Peter's Engineering College, Chennai, India \\ ${ }^{2}$ Department of Chemical Engineering, A M A College of Engineering, Kanchipuram, India \\ ${ }^{3}$ National Institute of Technology, Tiruchirappalli, India \\ Email: 'amslogin@gmail.com
}

\begin{abstract}
An experimental work is carried out for air-water system in 1-2 shell and tube heat exchanger with variable configuration for the passage of heating and test fluids with parallel and countercurrent flow. Two-phase parameters such as quality, LockhartMartinelli (L-M) parameter and two-phase multiplier were determined. Results showed that the heat transfer coefficient increases with quality for two-phase flow for the range of Reynolds number and quality studied. The L-M parameter is inversely proportional to quality. The two-phase multiplier shows a decreasing trend with increase in L-M parameter as reported in literature, Salcuden et al. [1] From the correlation $h_{1}=a N_{R e}{ }^{m}$, the heat transfer coefficient for two-phase flow can be predicted using the Lockhart-Martinelli parameter - Quality correlation with an error of less than $12 \%$.
\end{abstract}

Keywords: Heat transfer, Two-Phase multiplier, Tube heat exchanger

\section{INTRODUCTION}

Simultaneous flow of two or more immiscible phases is termed as multiphase flow. Systems involving multiphase fluid flow occur widely in nature and in industry. The two-phase flow is considered to be the common class of multiphase flow. Heat transfer involving two phases such as liquid-gas is of vital importance especially in petrochemical and allied industries. The presence of a gas phase along with liquid alters not only the fluid dynamic behavior but also the heat transfer characteristics namely, the heat transfer coefficient. Two-phase flow has found wide applications in environmental, chemical and biochemical process in the last decade [2].

The structure of two-phase flow is quite complicated and its flow parameters are described mostly in terms of empirical correlations [3]. A review by Jensen [4] revealed that there are no published data on two-phase flow heat transfer in shell and tube heat exchanger for quality and heat transfer coefficient.

Rani Hemamalini et al. [5] conducted an experimental study on two-phase flow through a pipe and control valve in series for air-palm oil system. They have found that, if data on the single phase flow through the pipe/valve is known for different flow rates it can be used to predict the pressure drop for two-phase flow based on the pure component density, gas and liquid flow rates.

In order to gain fundamental knowledge about the complex nature of two-phase flow behavior more so in heat transfer equipments, experimental work is essential. In the present work on 1-2 shell and tube heat exchanger for air-water system heat transfer characteristics of two- phase and single phase flow for parallel and countercurrent flow for different configurations such P2S, P2T, C2S, C2T, P1S, P1T, C1S and C1T has been studied. The two-phase parameters such as LockhartMartinelli parameter [6], quality and two-phase multiplier were determined. A dimensionless correlation is established between two-phase multiplier and LockhartMartinelli parameter to predict two-phase heat transfer coefficient based on pure component heat transfer correlation with Reynolds number.

\section{EXPERIMENTAL UNIT}

The experimental set-up is shown in Figure 1. It has provisions to study parallel and countercurrent flow with device to inject air and cold liquid at varying flow rates. The heating liquid is hot water which can flow either in shell or tube side and its flow rate is kept constant. The test liquid (pure liquid) is pumped from the storage tank (12) using centrifugal pump (14) and its flow rate through the shell and tube side is varied using valves (10). Calibrated rotameters were connected to the air-line $(9 \mathrm{~A})$, test liquid storage tank (9B) and geyser line (9C) to measure the flow rate of air, test liquid and heating liquid respectively. In the two-phase flow operation, the Ingersoll Rand compressor (11) is used to supply atmospheric air, the _T_joint (21) is used for mixing air and test liquid. Temperatures were noted at inlet and outlet of both tube and shell side using digital temperature indicator (15). The temperature was measured with copper-constantan thermocouples at the inlet and exit flow. The unit also consists of jacketed vessel (20) to cool the test liquid to its original temperature before recycling. 


\section{TYPES OF FLOW AND CONFIGURATION}

Provisions were made in the experimental set-up to analyze both parallel and countercurrent flow as follows:

Type 1 : Single phase flow (1): P1S, P1T, C1S, and C1T

Type 2: Two-phase flow (2) : P1S, P1T, C1S and C1T

Here, $P, C, 1,2, S, T$ refers to parallel flow, countercurrent flow, single phase liquid, two-phase fluid, shell side and tube side respectively.

\section{EXPERIMENTAL PROCEDURE}

The experiments were carried out in a 1-2 shell and tube heat exchanger for air-water system. For studies on single phase flow, water is circulated and in two-phase flow, air along with test liquid is fed at different flow rates. The flow rate of test liquid (water) and air was varied from of $3.33 \times 10^{-5}$ to $1 \times 10^{-4}$ and $1 \times 10^{-4}$ to $4.18 \times 10^{-4} \mathrm{~m}^{3} / \mathrm{s}$ respectively. The heating liquid flow rate was kept constant at $2.5 \times 10^{-5} \mathrm{~m}^{3} / \mathrm{s}$. The different configurations and their range are given in Table 1.

Table 1. Parameters range of different configurations for air-water system

\begin{tabular}{|c|c|c|c|c|c|}
\hline Confgn. & $\begin{array}{l}\text { Two-phase heat } \\
\text { transfer } \\
\text { coefficient, } \mathrm{h}_{24} \\
\left.\left[\mathrm{~W} / \mathrm{m}^{2} \mathrm{~K}\right]\right]\end{array}$ & Quality, $X$ & $\begin{array}{l}\text { Two-phase } \\
\text { multiplier, } \Phi_{L}\end{array}$ & $\underset{\substack{\text { Larameter, } \\
x_{\mathrm{a}^{2}}}}{ }$ & $\begin{array}{l}\text { LMTD } \\
(\Delta T)_{h}\end{array}$ \\
\hline $\mathrm{P} 2 \phi \mathrm{S}$ & $84-280$ & $0.0024-0.0049$ & $0.3894-0.4545$ & $15.67-6.54$ & 18 \\
\hline$P 2 \phi T$ & $74-162.1$ & $0.0033-0.0065$ & $0.6279-0.6860$ & $18.98-7.37$ & 18.5 \\
\hline $\mathrm{C} 2 \phi \mathrm{S}$ & $192-373$ & $0.0041-0.0060$ & $0.8533-0.9521$ & 16.768 .9 & 18.4 \\
\hline $\mathrm{C} 2 \phi \mathrm{T}$ & $201-472$ & $0.0050-0.0080$ & $0.7899-0.8616$ & $12.56-9$ & 21.2 \\
\hline
\end{tabular}

The experiments were conducted for parallel and countercurrent flow. The heat transfer coefficients for different flow configurations for single and two-phase system were calculated. For two-phase system the following correlations have been established:
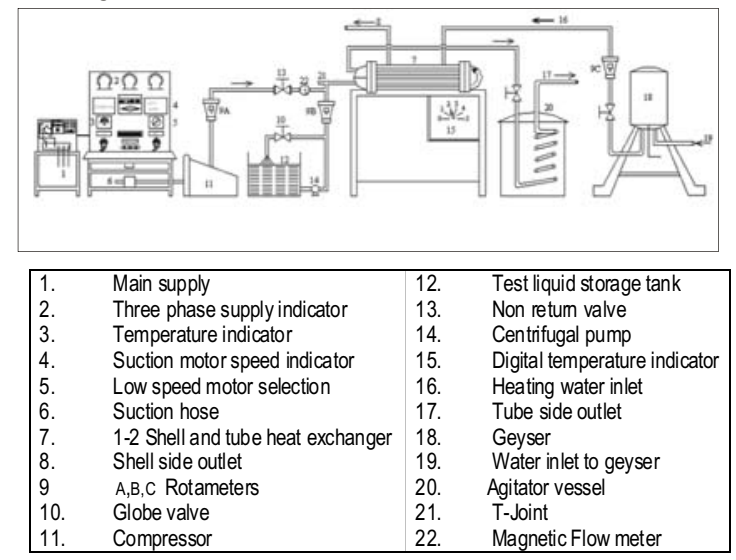

Fig. 1. Schematic diagram of the experimental unit a) Two-phase heat transfer coefficient, $h_{2}$ Vs Quality, $X$

b) Two-phase multiplier, $L$ Vs Quality, $X$

c) Lockhart-Martinelli parameter, $x_{\| t}^{2} V_{s}$ Quality, $X$

d) Two-phase multiplier, L Vs Lockhart-Martinelli (L-M) parameter, $x_{t t}^{2}$

\section{RESULTS AND DISCUSSION}

\section{Studies on Single Phase Flow:}

The test liquid was passed through four different configurations such as P1S, P1T, C1S and C1T. The data on temperature and flow rates of the test and hot fluid were experimentally noted. The heat transfer coefficient for the test fluid was calculated using equations 1 to 8 .

$$
\begin{aligned}
& \mathrm{N}_{\mathrm{Re}}= \\
& \mathrm{N}_{\mathrm{Pr}}=\frac{D V \rho}{\mu} \\
& \mathrm{N}_{\mathrm{gz}}=\frac{C_{p} \mu}{K} \\
& \mathrm{~N}_{\mathrm{nu}}= \\
& \mathrm{N}_{\mathrm{Pe}}=\frac{h_{i} D}{\bigwedge_{\mathrm{pe}}} \times \mathrm{N}_{\mathrm{pr}} \\
& \mathrm{Q}_{\mathrm{i}}=\mathrm{U}_{\mathrm{i}} \mathrm{A}_{\mathrm{i}}(\mathrm{T})_{\mathrm{ln}} \\
& 1 / \mathrm{U}_{\mathrm{i}}=\left(1 / \mathrm{h}_{\mathrm{i}}\right)+\left(1 / \mathrm{h}_{0}\right)\left(\mathrm{A} / \mathrm{A}_{0}\right) \\
& \mathrm{N}_{\mathrm{Nu}}=2.0 \mathrm{~N}_{\mathrm{Gz}}^{0.3} \\
& \mathrm{D}_{\mathrm{e}}=4 \times \mathrm{r}_{\mathrm{H}}
\end{aligned}
$$

Since the flow was laminar Equation 8 is used to calculate the heat transfer coefficient ' $h$ ' of the test fluid on tube and shell side. However for the passage of test fluid through shell side an equivalent diameter given by equation 9 was used to determine velocity. Figure 2 is a plot of heat transfer coefficient of test liquid as a function of Reynolds number for the test liquids studied. A general relation of the form was arrived by regression analysis.

$h_{1}=a N_{R e}{ }^{m}$

The relevant relations and values are given in Figure 2 and Table 1 respectively.

From the results it is seen for test liquid that the heat transfer co-efficient is a maximum under countercurrent flow. Water gives higher heat transfer coefficient because of its high thermal conductivity, low viscosity and also the 
logarithmic mean temperature difference is maximum in countercurrent flow.

\section{Studies on Two-Phase Flow:}

For two-phase studies, the properties of the mixture of water and air are taken as weighted average of the test fluid properties at respective temperatures, [7].

$$
\begin{aligned}
k & =k_{1} x_{1}+K_{2} x_{2} \\
& ={ }_{1} x_{1}+{ }_{2} x_{2} \\
& ={ }_{1} x_{1}+{ }_{2} x_{2} \\
C p & =C p_{1} x_{1}+C p_{2} x_{2}
\end{aligned}
$$

The relations involved in various calculations for twophase flow are given by equations 15 to 18 .

$$
\begin{aligned}
& \text { Quality, } X=\overline{\left(1+\frac{\rho_{L}}{\rho_{G}} \frac{Q_{L}}{Q_{G}}\right)} \\
& \text { Two-phase multiplier, } L=\frac{h_{2 \phi}}{h_{1 \phi}}
\end{aligned}
$$

Two-phase heat transfer coefficien

$$
\text { Single phase heat transfer coefficient }
$$

$$
\Phi_{\mathrm{L}}=\frac{h_{2 \phi}}{h_{1 \phi}}=1+\frac{C}{x_{t t}}+\frac{1}{x_{t t}^{2}}
$$

$$
\text { Lockhart-Martinelli }(\mathrm{LM}) \text { parameter }=\mathrm{x}_{\mathrm{tt}}^{2}=
$$

The flow regime is stratified for the system studied with air flow rate of $1 \times 10^{-4}-4.18 \times 10^{-4} \mathrm{~m}^{3} / \mathrm{s}$ and test liquid flow rate of $3.33 \times 10^{-5}-1 \times 10^{-4} \mathrm{~m}^{3} / \mathrm{s}$ as found in literature Vlasogiannis et al. [8]. Figure 2 shows the variation of single phase heat transfer coefficient with Reynolds number. The value of slope $m$ is given in Table 2. Figure 3 and 4 present graphically the two-phase heat transfer coefficient with Reynolds number and Quality X. Figure 5 and 6 shows the variation of two phase multiplier with quality and LM parameter. Figure 7 is reconstructed from Fig. 5 and 6 . The data was fitted by regression analysis and the constants are shown in the respective figures. The increase of two-phase multiplier with quality is in agreement with literature Salcudean et al. [1]. The increase in two-phase heat transfer coefficient in the range of quality studied may be due to increased turbulence. At higher air rates (higher quality) this may not be the case since a film heat transfer coefficient may predominate.
This is the work which is being pursued in this laboratory.

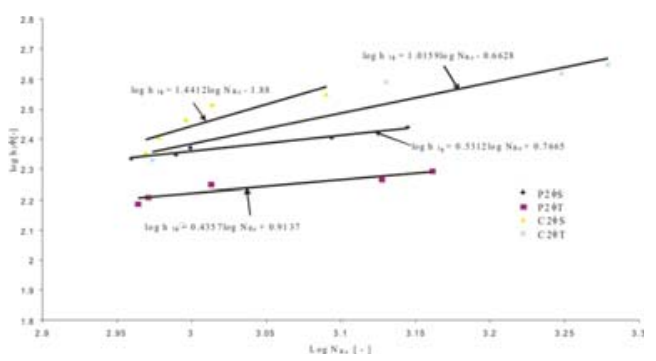

Fig. 2. $\log h 1$ Vs Log NRe of pure water for different configurations

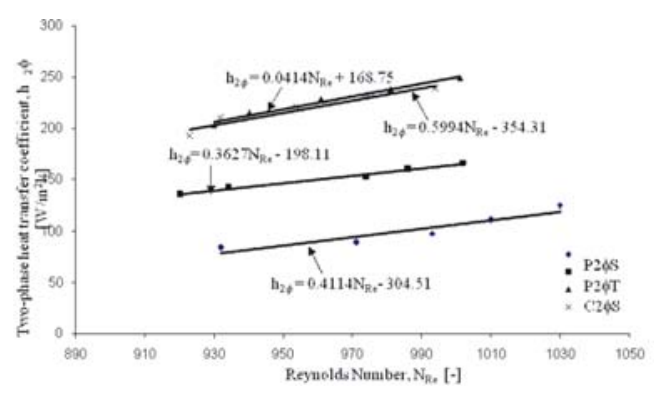

Fig. 3. Two-phase heat transfer coefficient Vs Reynolds number of air-water system for different configurations

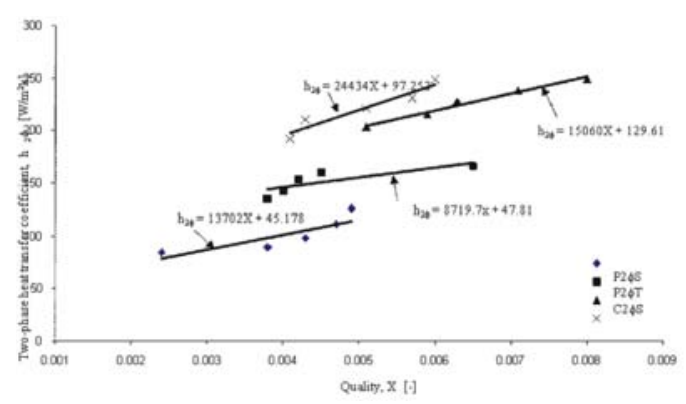

Fig. 4. Two-phase heat transfer coefficient Vs Quality of air-water system for different configurations

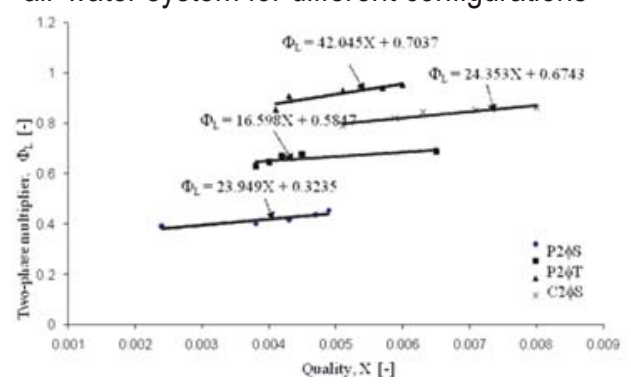

Fig. 5. Two-phase multiplier Vs Quality of air-water system for different configurations 


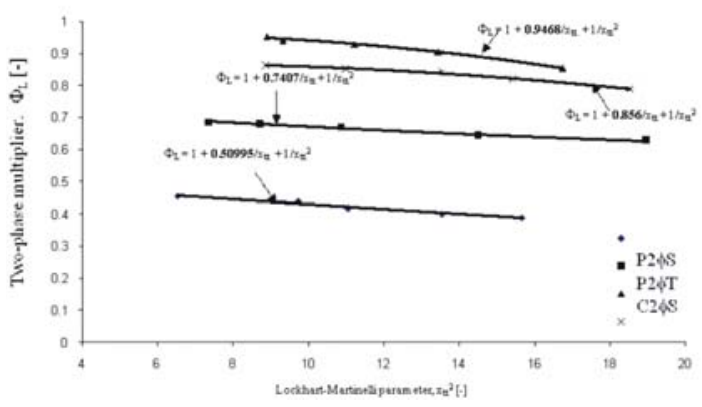

Fig. 6. Two-phase multiplier Vs L-M parameter of air-water system for different configurations

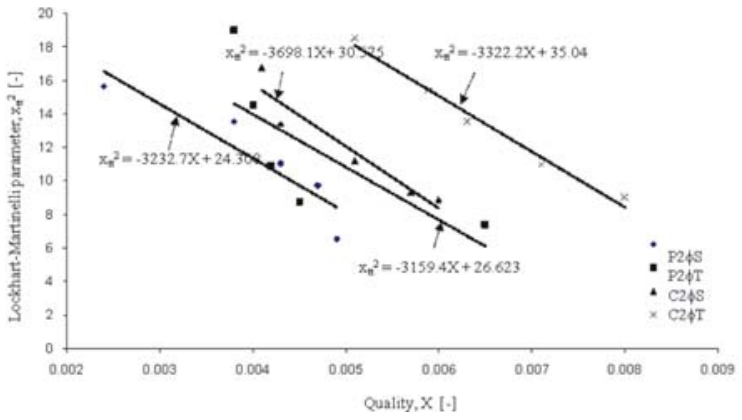

Fig. 7. L-M parameter Vs Quality of air-water system for different configurations

\section{CONCLUSION}

1. Two-phase flow through 1-2 shell and tube heat exchanger has been studied for water with air as gas phase. The experimental results showed that twophase heat transfer coefficient increases with quality.

2. The results of single-phase and two-phase flow heat transfer show that present experimental set-up is reliable.

3. The correlations have been established for Twophase heat transfer coefficient $V s$ quality, Two-phase multiplier Vs quality, Two-phase multiplier Vs L-M parameter and Lockhart-Martinelli (L-M) parameter Vs quality.

4. The two-phase multiplier shows a decreasing trend with increase in L-M parameter.

5. If the data on single phase is known for different flow rates it can be used to generate data on heat transfer co-efficient for two phase flow based on the pure component density, gas and liquid flow rates. Error ranges from 0.44 to 12 percent.

\section{REFERENCES}

[1] Salcudean, M. E., 1984, "Effect of Flow Obstructions on Flow Transitions and Pressure Drop in Two-phase Flow"s, Int. journal of heat and mass transfer, pp.715-769, (Published paper)

[2] Fairhurst, C.P.,1983, Component Pressure Loss during Two-phase Flow', Proc. of Int. Conference on the Physical Modeling of Multiphase Flow, England, pp.1-24. (Proceedings)

[3] Collier, 1981, A Multi Dimensional Model for GasLiquid Flow, Chemical Engineering Science, pp.3577-3589. (Article)

[4] Jensen, M.K.,1988, "One Dimensional Two-Phase Flow", AICHE symposium series, vol.84, pp.114-119 (Proceedings)

[5] Rani Hemamalini, R., Partheeban, P., Sarat Chandra Babu, J. and Sundaram, S., 2005, The Effect on Pressure Drop across Horizontal Pipe and Control Valve for Air/Palm oil two phase-flow, Int. journal of heat and mass transfer, vol.48, pp. 2911-2921. (Published paper)

[6] Lockhart, R.W. and Martinelli, R.C.,1949, Proposed Correlation of Data for Isothermal "Two-Phase Two Component Flow in Pipes", Chemical Engineering progress, vol. 45, pp.39-48. (Article)

[7] Perry, R.H., Green, D.G., and Maloney, J.O., 1997, Perry's Chemical Engineers Handbook, $7^{\text {th }}$ Edition, pp.621-650. (Book)

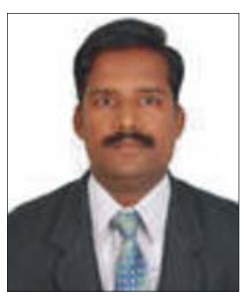

A.M. Saravanan is working as a Professor and Head in the Department. of Chemical Engineering, St.Peter's Engineering College, Chennai. He has received the Career Award for Young Teachers from All India Council of Technical Education in 2008. To his credit he has published 35 papers in International and National level journals and conferences. He has carried out several projects funded from AICTE, DST, DRDO, MHRD, TNSCST etc. and also organized conferences, STP and workshops. 